\title{
Phosphorylation of osteopontin has proapoptotic and proinflammatory effects on human knee osteoarthritis chondrocytes
}

\author{
SHU-GUANG GAO ${ }^{1 *}$, YANG YU $^{1,2^{*}}$, CHAO ZENG $^{1 *}$, SHI-TAO LU ${ }^{1,2}$, JIAN TIAN $^{1}$, \\ CHAO CHENG ${ }^{1,3}$, LIANG-JUN LI ${ }^{1,4}$ and GUANG-HUA LEI ${ }^{1,5}$ \\ ${ }^{1}$ Department of Orthopedics, Xiangya Hospital, Central South University, Changsha, Hunan 410008; \\ ${ }^{2}$ Department of Orthopedics, The First Affiliated Hospital of Zhengzhou University, Zhengzhou, Henan 450000; \\ ${ }^{3}$ Department of Orthopedics, Yiyang Central Hospital, Yiyang, Hunan 413000; \\ ${ }^{4}$ Department of Orthopedics, Changsha Central Hospital, Changsha, Hunan 410004; \\ ${ }^{5}$ Research Center of Clinical Skills of Joint Surgery of Hunan Province, Changsha, Hunan 410008, P.R. China
}

Received July 8, 2015; Accepted September 9, 2016

DOI: $10.3892 / \mathrm{etm} .2016 .3784$

\begin{abstract}
The aim of the present study was to investigate the effects of phosphorylated osteopontin (p-OPN) on apoptosis and pro-inflammatory cytokine expression in human knee osteoarthritis (OA) chondrocytes. Human knee OA chondrocytes obtained from patients who underwent total knee arthroplasty were treated with p-OPN, OPN or buffer. Reverse transcription quantitative-polymerase chain reaction (RT-qPCR) and western blot analysis were used to assess the expression levels of proinflammatory factors, including interleukin (IL)-1 $\beta$, tumor necrosis factor (TNF)- $\alpha$, IL- 6 and nuclear factor $(\mathrm{NF})-\kappa \mathrm{B}$. Apoptosis of human knee OA chondrocytes was detected by Annexin V-fluorescein isothiocyanate/propidium iodide flow cytometry. Compared with the controls, chondrocytes treated with OPN exhibited higher mRNA and protein expression levels of proinflammatory factors (IL-1 $\beta$, TNF- $\alpha$, IL- 6 and NF- $\kappa$ B), and a higher percentage of apoptotic chondrocytes. Furthermore, chondrocytes treated with p-OPN exhibited the highest mRNA and protein expression levels of proinflammatory factors (IL-1 $\beta, \mathrm{TNF}-\alpha, \mathrm{IL}-6, \mathrm{NF}-\kappa \mathrm{B}$ ) and the highest percentage of apoptotic chondrocytes. $\mathrm{p}$-OPN induces chondrocyte apoptosis and proinflammatory factor release, which suggests that $\mathrm{p}-\mathrm{OPN}$ may contribute to OA pathogenesis, and inhibition of p-OPN may provide a novel effective strategy to slow or halt OA progression.
\end{abstract}

Correspondence to: Professor Guang-Hua Lei, Department of Orthopedics, Xiangya Hospital, Central South University, 87 Xiangya Road, Changsha, Hunan 410008, P.R. China

E-mail: lgh9640@sina.cn

${ }^{*}$ Contributed equally

Key words: osteopontin, phosphorylation, osteoarthritis, chondrocyte, apoptosis

\section{Introduction}

Osteoarthritis (OA) is a complex degenerative joint disease that characterized by the progressive loss of articular cartilage that leads to chronic pain and functional limitations. The prevalence of OA has markedly increased in the past two decades due to an ageing population and increasing obesity, and the public health consequences of OA and OA-associated disability are expected to increase as a result of the increasing incidence of obesity and the aging of the population (1-3). However, the molecular mechanisms underlying OA remain to be fully elucidated. Several biochemical and biomechanical factors are thought to underlie OA pathogenesis.

OPN (osteopontin) is a 44-75 KD multifunctional phosphoprotein secreted by numerous cell types, including osteoclasts, macrophages, lymphocytes, epithelial cells and vascular smooth muscle cells (SMC) (4-5). This protein, also known as early $\mathrm{T}$ cell activation gene- 1 is abundant in bone, where it mediates important cell-matrix and cell-cell interactions (5). During the past two decades, OPN has become the subject of increased research in OA pathogenesis. Previous studies have demonstrated a close association between OPN and OA (6-17), which suggests OPN may serve as a biochemical marker of disease severity in knee OA. In addition, the functions of OPN are tightly regulated by its phosphorylation status in normal and pathological states (4). OPN phosphorylation has been demonstrated to regulate cell adhesion and migration (18-21). Furthermore, the different types and the extent of OPN phosphorylation contribute to the greater complexity of OPN-receptor binding and downstream signaling pathways (18). Xu et al (22) revealed that OA cartilage had higher phosphorylation levels of OPN compared with normal cartilage, OPN increases matrix metalloproteinase (MMP)-13 expression, and the upregulation of MMP-13 expression induced by phosphorylated (p)-OPN was more marked than that induced by non-phosphorylated OPN. Further studies are required in order to elucidate the detailed molecular mechanisms underlying the effect of $\mathrm{p}$-OPN on cartilage degeneration. 
Apoptosis, or genetically programmed cell death, has been associated with OA $(23,24)$. Since chondrocytes are the only resident cells located in articular cartilage and are responsible for both the synthesis and the breakdown of the extracellular matrix (ECM) and tissue function (25), research to elucidate the detailed mechanism underlying apoptosis in cartilage is of great significance for understanding OA pathogenesis (26). Dalal et al (27) reported that OPN stimulates apoptosis in adult cardiac myocytes via the involvement of CD44 receptors. However, to date no investigation into the roles of $\mathrm{p}$-OPN in apoptosis and pro-inflammatory cytokines in human chondrocytes have been reported.

The aim of the present study was to investigate the effects of p-OPN on apoptosis and pro-inflammatory cytokine expression of human knee OA chondrocytes, which may serve as a useful tool to mark the OA disease process and to further elucidate the molecular changes and signaling pathways underlying OA.

\section{Materials and methods}

OA cartilage acquisition. OA cartilage samples were obtained from the knees of patients $(n=16 ; 6$ males and 10 females; mean age, $63.5 \pm 10.3$ years) during total knee arthroplasty at Xiangya Hospital (Changsha, China) between January 2014 and June 2014. Clinical data were carefully reviewed to exclude any secondary forms of OA, rheumatoid arthritis or other arthritis forms. The cartilage samples were macroscopically altered and histological analysis of representative samples showed typical OA changes, such as focal cell loss, chondrocyte cluster formation and fibrillation. The present study was approved by the ethics committee of the Xiangya Hospital. All patients willing to donate knee tissue samples provided written-informed consent.

p-OPN preparation. Phosphorylation of recombinant osteopontin increases its ability to support osteoclast adhesion and cell attachment, which is dependent on an RGD sequence to the same extent as the native phosphorylated osteopontin (28). Therefore, mitogen-activated protein kinase (MAPK) was used to obtain phosphorylated exogenous OPN. rhOPN (R\&D Systems, Inc., Minneapolis, MN, USA) was diluted with phosphate-buffered saline (PBS) to $0.1 \mu \mathrm{g} / \mathrm{ml}$. The diluted OPN $(5 \mu \mathrm{l})$ was phosphorylated in a total volume of $50 \mu \mathrm{l}$ containing 10 mM ATP $(10 \mu \mathrm{l}), 1 \mu \mathrm{l}$ MAPK (Thermo Fisher Scientific, Inc., Waltham, MA, USA) 10X kinase buffer $[25 \mathrm{mM}$ Tris- $\mathrm{HCl}$ ( $\mathrm{pH} 7.5$ ), $5 \mathrm{mM} \beta$-glycerophosphate, $2 \mathrm{mM}$ dithiothreitol, $\left.0.1 \mathrm{mM} \mathrm{Na}_{3} \mathrm{VO}_{4}, 10 \mathrm{mM} \mathrm{MgCl}{ }_{2}\right]$ at $30^{\circ} \mathrm{C}$ for $30 \mathrm{~min}$. The phosphorylation was terminated by adding $10 \mu \mathrm{l}$ of stop mixture (1\% SDS and $100 \mathrm{mM}$ EDTA). These reagents were purchased from Cell Signaling Technology Inc. (Danvers, MA, USA).

Cell isolation and culture conditions. OA cartilage samples were cut from the subchondral bone and homogenized to form pieces $<1 \mathrm{~mm}^{3}$, prior to being treated with $2 \%$ penicillin/streptomycin and $0.2 \%$ amphotericin B (Gibco; Thermo Fisher Scientific, Inc.) in Dulbecco's modified Eagle's medium (DMEM; Thermo Fisher Scientific, Inc.). OA chondrocytes were isolated from the OA articular cartilage using a sequential enzymatic digestion with $0.1 \%$ hyaluronidase for $30 \mathrm{~min}$, then $0.5 \%$ pronase for $1 \mathrm{~h}$, and $0.2 \%$ collagenase (Gibco; Thermo Fisher Scientific, Inc.) for $1 \mathrm{~h}$ at $37^{\circ} \mathrm{C}$ carried out in the washing solution (DMEM, penicillin/streptomycin and amphotericin B). The suspension was then filtered twice through a $70 \mu \mathrm{m}$ nylon mesh, washed twice with $4^{\circ} \mathrm{C}$ PBS, and centrifuged at $450 \mathrm{x} \mathrm{g}$ for $10 \mathrm{~min}$ at $4^{\circ} \mathrm{C}$. A trypan blue viability test was conducted and demonstrated that $93 \%$ of the recovered cells were alive. The primary cultures of chondrocytes were kept at $37^{\circ} \mathrm{C}$ in an atmosphere containing $5 \% \mathrm{CO}_{2}$ for 2 weeks.

Treatments. Human OA chondrocytes at first passage were seeded on a 24-well plate at a starting density of $1 \times 10^{4}$ cells/well with two medium changes (DMEM) per week until they became confluent. The cells were then divided into three groups: (1) The p-OPN group, treated with $4 \mu \mathrm{g} / \mathrm{ml}$ p-OPN for $48 \mathrm{~h}$ as previously described (23); (2) the OPN group, treated with $4 \mu \mathrm{g} / \mathrm{ml}$ OPN (R\&D Systems, Inc.) for $48 \mathrm{~h}$ as previously described $(15,16,23)$; and (3) the control group, stimulated with $4 \mu \mathrm{g} / \mathrm{ml}$ buffer (Cell Signaling Technology, Inc.) for $48 \mathrm{~h}$.

Apoptosis assay. The frequency of chondrocyte apoptosis was measured by flow cytometry with Annexin V-fluorescein isothiocyanate (FITC) and propidium iodide (PI; both from Roche Diagnostics GmbH, Mannheim, Germany). A total of $1 \times 10^{4}$ treated chondrocytes were collected from each group, washed in cold PBS and incubated with Annexin V-FITC and $\mathrm{PI}$ at room temperature for $15 \mathrm{~min}$ in the dark on ice. These samples were then analyzed using a fluorescence-activated cell sorter (BD Biosciences, San Jose, CA, USA). Cell Quest software (version 7.5.3; BD Biosciences) was used to analyze the percentage of apoptosis. All tests were repeated in triplicate.

RNA isolation and reverse transcription-quantitative polymerase chain reaction ( $R T-q P C R)$. Total RNA was extracted from OA chondrocytes following treatments using TRIzol reagent (Invitrogen; Thermo Fisher Scientific, Inc.) according to the manufacturer's instructions. Total RNA $(1 \mu \mathrm{g})$ was quantified by spectrophotometry and reverse transcribed to cDNA using an AllinOne ${ }^{\mathrm{TM}}$ First Strand cDNA Synthesis kit (GeneCopoeia, Inc., Rockville, MD, USA). RT-qPCR was performed using a SYBR Green qPCR SuperMix (GeneCopoeia, Inc.) and ABI 7900 Sequence Detection system (Applied Biosystems; Thermo Fisher Scientific, Inc.). The qPCR thermal cycling conditions were as follows: Initial denaturation at $95^{\circ} \mathrm{C}$ for $10 \mathrm{~min}$, followed by 40 cycles of denaturation at $95^{\circ} \mathrm{C}$ for $15 \mathrm{sec}$, annealing at $60^{\circ} \mathrm{C}$ for $30 \mathrm{sec}$ and extension at $72^{\circ} \mathrm{C}$ for $30 \mathrm{sec}$. Melting curve analysis was performed following the final amplification period via a temperature gradient of $95^{\circ} \mathrm{C}$ for $15 \mathrm{sec}, 60^{\circ} \mathrm{C}$ for $15 \mathrm{sec}$ and $95^{\circ} \mathrm{C}$ for $15 \mathrm{sec}$. The specific primers used for the various human mRNAs (GenScript, Nanjing, China) were: Interleukin (IL)-1 $\beta$ forward, 5'-CGTTCCCATTAGACAACTGCA-3', and reverse, 5'-GGTATAGATTCTTTCCTTTGAGGC-3'; tumor necrosis factor (TNF)- $\alpha$ forward, 5'-AAAGCATGATCCGAG ATGTGTGGAA-3', and reverse, 5'-AGTAGACAGAAGAGC GTGGTGGC-3'; IL-6 forward, 5'-CCAGTTGCCTTCTTG GGACT-3', and reverse, 5'-GTCTGTTGTGGGTGGTATCCT CTGT-3'; nuclear factor (NF)- $\kappa$ B forward, 5'-CCCATCGGG TTCCCATAAAG-3', and reverse, 5'-GCCTGAAGCAAATGT 
A

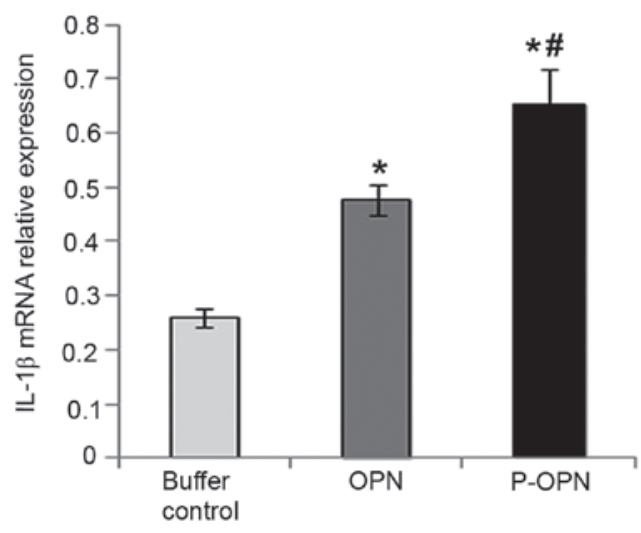

C

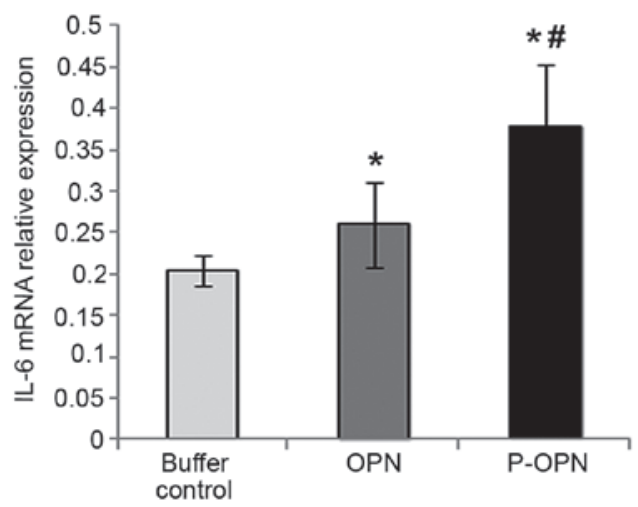

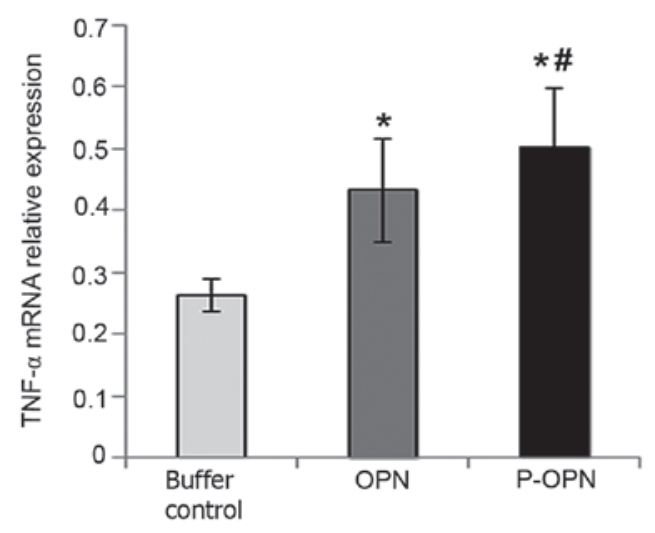

D

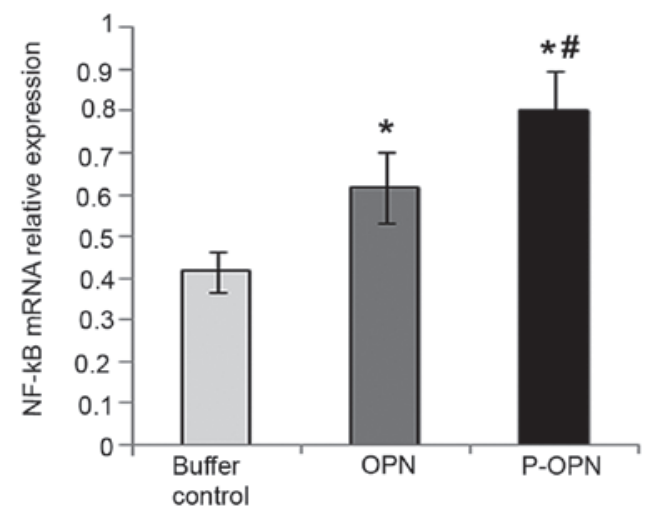

Figure 1. p-OPN and OPN increase the relative mRNA expression levels of (A) IL-1 $\beta$, (B) TNF- $\alpha$, (C) IL-6 and (D) NF-kB in OA chondrocytes. Reverse transcription-quantitative polymerase chain reaction was carried out to determine the relative mRNA expression levels of pro-inflammatory factors (IL-1 $\beta$, TNF- $\alpha$, IL-6 and NF- $\mathrm{kB}$ ) in chondrocytes treated for $48 \mathrm{~h}$ with p-OPN, OPN and buffer. For comparative purposes, mRNA expression levels in buffer-treated cells were normalized to 1 . Error bars represented fold changes in the mRNA expression of IL-1 $\beta$, TNF- $\alpha$, IL- 6 and NF- $\kappa$ B following normalization with the expression levels of buffer-treated OA chondrocytes. Samples from three independent experiments were measured. Results were provided as means \pm standard deviation. ${ }^{\text {P }}<0.05$, vs. the control; ${ }^{*} \mathrm{P}<0.05$, vs. the OPN group. p-OPN, phosphorylated osteopontin; IL, interleukin; TNF, tumor necrosis factor; NF, nuclear factor; OA, osteoarthritis.

TGGCGTA-3'; and $\beta$-actin forward, 5'-CATCCTGCGTCT GGACCTGG-3', and reverse, 5'-TAATGTCACGCACGATTT CC-3'. The data were given as a quantitative cycle (Cq). IL-1 $\beta$, TNF- $\alpha$, IL-6 mRNA and NF- $\kappa$ B mRNA expression levels were normalized to $\beta$-actin mRNA controls using the comparative $2^{-\Delta \Delta \mathrm{Cq}}$ method (29).

Western blot analysis. Total proteins were extracted from the cells using whole-cell ice-cold lysis buffer containing $50 \mathrm{mM}$ Tris- $\mathrm{HCl}, \mathrm{pH} 7.4,1 \% \mathrm{NP}-40,150 \mathrm{mM} \mathrm{NaCl}$ and $0.1 \%$ SDS supplemented with proteinase inhibitor (one tablet/10 ml; Roche Diagnostics, Indianapolis, IN, USA). For the western blot analysis, $40 \mu \mathrm{g}$ of protein extracts were size-fractionated by $4-20 \%$ SDS-PAGE, and transferred onto nitrocellulose membranes (Invitrogen; Thermo Fisher Scientific, Inc.). The membrane was blocked with $5 \%$ bovine serum albumin in Tris-buffered saline with Tween 20 (TBST) for $1 \mathrm{~h}$. The membranes were then incubated with the following primary antibodies for $24 \mathrm{~h}$ at $4^{\circ} \mathrm{C}$ : Anti-IL-1 $\beta$ (1:1,000; cat. no. 12242 ; Cell Signaling Technology, Inc.), TNF- $\alpha$ (1:1,000; cat. no. 37078; Cell Signaling Technology, Inc.), IL-6 (1:100; cat. no. 12153; Cell Signaling Technology, Inc.), NF-кB (1:500; cat. no. 8242; Cell Signaling Technology, Inc.) and $\beta$-actin (1:4,000; cat. no. 8457; Cell Signaling Technology, Inc.). The membranes were then washed with TBST for 5 min 3 times and incubated with horseradish peroxidase-conjugated anti-mouse or rabbit secondary antibody (1:1,000; cat. no. sc-2030; Santa Cruz Biotechnology, Inc., Dallas, TX, USA). The proteins were detected by a chemiluminescence system using an enhanced chemiluminescence (ECL) reagent Pierce ECL Western Blotting Substrate (Thermo Fisher Scientific, Inc.). Intensity of the bands was quantified using Quantity One software (version 4.2.3; Bio-Rad Laboratories, Inc., Hercules, CA, USA).

Statistical analysis. Data were expressed as means \pm standard deviation. Statistical analysis was performed with SPSS 15.0 statistical software (SPSS Inc., Chicago, IL, USA). Comparisons between two groups were made using Student's $t$-test. One-way analysis of variance followed by Student-Newman-Kuels test was utilized to determine the significant difference between multiple groups. $\mathrm{P}<0.05$ was considered to indicate a statistically significant result.

\section{Results}

Effect of $O P N$ and its phosphorylation on the relative $m R N A$ expression levels of pro-inflammatory factors. As shown in Fig. 1, the relative mRNA expression levels of IL-1 $\beta$, 
A

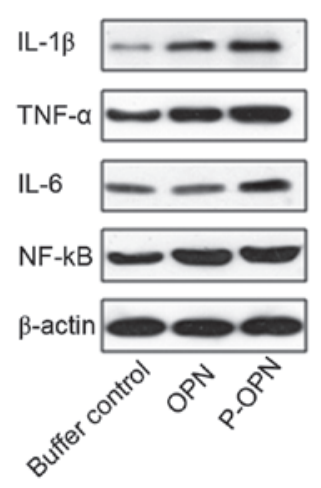

B

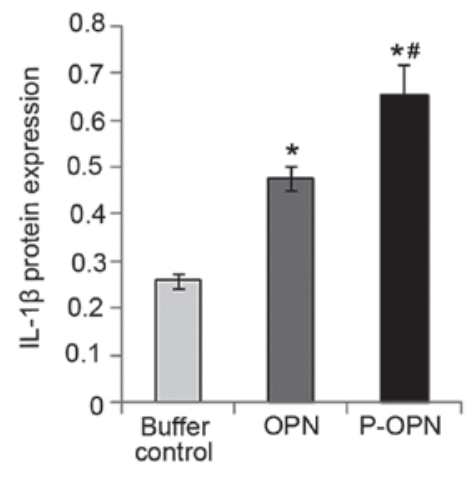

D

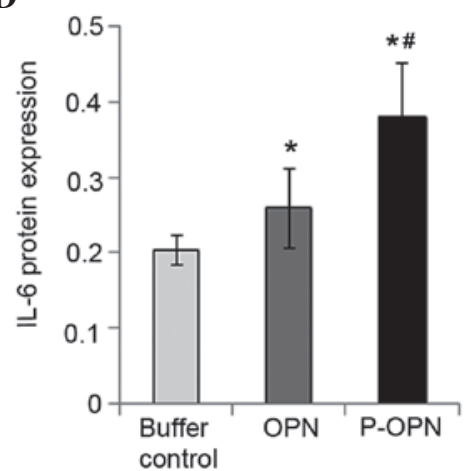

C

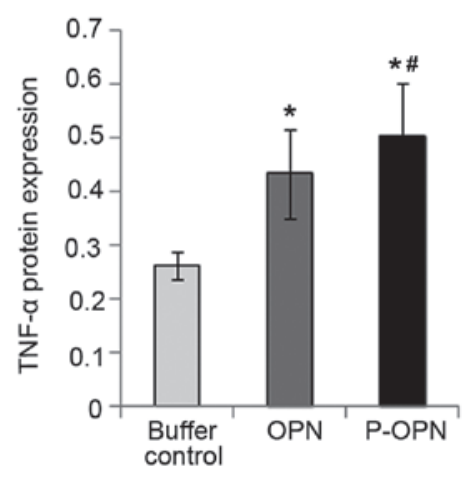

E

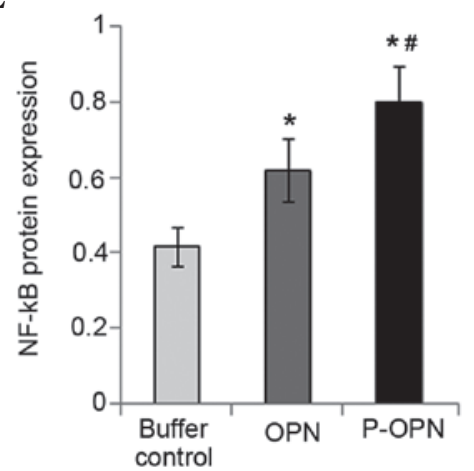

Figure 2. p-OPN and OPN increase the protein expression levels of pro-inflammatory factors in OA chondrocytes. (A) Western blotting was carried out to determine the protein expression levels of IL-1 $\beta$, TNF- $\alpha$, IL-6 and NF- $\kappa$ B in chondrocytes treated for $48 \mathrm{~h}$ with p-OPN, OPN and buffer. Bars represented the fold changes in protein expression of (B) IL- $1 \beta$, (C) TNF- $\alpha$, (D) IL- 6 and (E) NF- $\kappa$ B following normalization with the expression levels of $\beta$-actin in the OA chondrocytes. Samples from three independent experiments were measured. Results were given as means \pm standard deviation. $\mathrm{P}<0.05$, vs. the control; ${ }^{\#} \mathrm{P}<0.05$, vs. the OPN group. p-OPN, phosphorylated osteopontin; IL, interleukin; TNF, tumor necrosis factor; NF, nuclear factor; OA, osteoarthritis.

TNF- $\alpha$, IL- 6 and NF- $\kappa$ B in the OPN group (1.744 \pm 0.125 -fold, 1.522 \pm 0.086 -fold, 1.204 \pm 0.027 -fold and 1.880 \pm 0.052 -fold, respectively) were significantly higher compared with the control group $(\mathrm{P}<0.05)$. Furthermore, $\mathrm{p}-\mathrm{OPN}$-treated chondrocytes exhibited enhanced relative mRNA expression levels of IL-1 $\beta$, TNF- $\alpha$, IL-6 and NF- $\kappa$ B $(2.295 \pm 0.087$-fold, $1.761 \pm 0.076$-fold, $1.444 \pm 0.076$-fold and 2.423 \pm 0.083 -fold, respectively) compared with the buffer control group $(\mathrm{P}<0.05)$. In addition, Fig. 1 shows that chondrocytes treated with p-OPN exhibited a significant increase the relative mRNA expression levels of IL-1 $\beta$, TNF- $\alpha$, IL- 6 and NF- $\kappa$ B compared with cells in the OPN group $(\mathrm{P}<0.05)$. Therefore, OPN upregulates the expression of pro-inflammatory factors (IL-1 $\beta$, TNF- $\alpha$, IL-6 and $\mathrm{NF}-\kappa \mathrm{B})$ at the gene level and the effects are associated with the state of phosphorylation.

Effect of OPN and its phosphorylation on the protein expression levels of pro-inflammatory factors. To determine the effect of OPN phosphorylation on the protein expression of pro-inflammatory factors, western blotting was employed to measure the protein expression levels of IL-1 $\beta$, TNF- $\alpha$, IL-6 and NF- $\mathrm{NB}$ in all three groups of OA chondrocytes (Fig. 2). The highest protein expression levels of pro-inflammatory factors were found in chondrocytes treated with p-OPN $(\mathrm{P}<0.05)$, although OPN-treated chondrocytes also exhibited significantly increased pro-inflammatory factor expression levels $(\mathrm{P}<0.05)$. Upregulation of the protein expression of pro-inflammatory factors detected in chondrocytes treated with OPN (whether phosphorylated or not) suggests that OPN activates the protein expression of pro-inflammatory factors. However, the 2-3-fold upregulation of the protein expression levels of pro-inflammatory factors detected in chondrocytes treated with p-OPN suggests the activation of pro-inflammatory factors not only relies on the quantity of OPN, but also on post-translational phosphorylation. Therefore, OPN upregulates the expression of pro-inflammatory factors (IL-1 $\beta$, TNF- $\alpha$, IL- 6 and NF- $\kappa$ B) at the protein level and the effects are associated with the state of phosphorylation.

Effect of OPN and its phosphorylation on the apoptosis of human OA chondrocytes. To examine the effect of OPN phosphorylation on OA chondrocyte apoptosis, flow cytometry staining with Annexin V-FITC/PI was employed to detect chondrocyte apoptosis in all three groups (Fig. 3). Compared with the buffer control group, treatment with OPN or p-OPN for $48 \mathrm{~h}$ caused an increase in the percentage of Annexin V-positive cells $(\mathrm{P}<0.05$; Fig. 3). Furthermore, the percentage of Annexin V-positive cells in the p-OPN group was higher compared with that of the OPN group $(\mathrm{P}<0.05)$. Therefore, OPN treatment increases human OA chondrocyte apoptosis and the effects are associated with the state of phosphorylation.

\section{Discussion}

OPN is found predominantly as a secreted protein expressed by various types of cells, and is present in the majority of tissues 
A

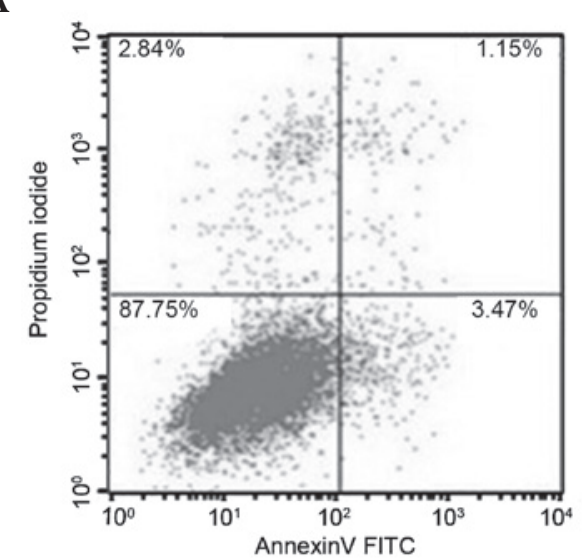

C

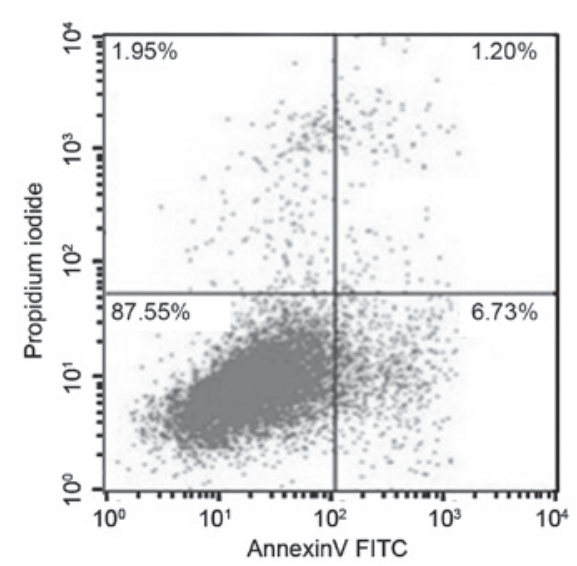

B

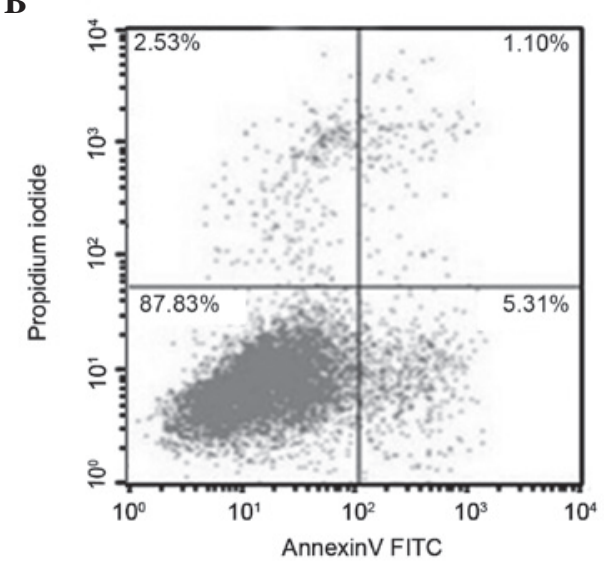

D

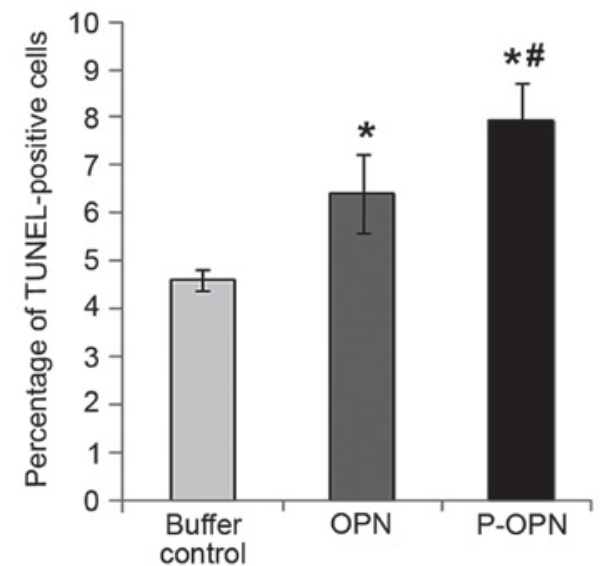

Figure 3. p-OPN and OPN increase OA chondrocyte apoptosis. Chondrocytes were treated with (A) buffer, (B) OPN and (C) P-OPN for 48 h. (D) Apoptosis of chondrocytes was measured by flow cytometric analysis of cells labeled with Annexin V-FITC/PI double staining. All data are presented as means \pm standard deviation. ${ }^{*} \mathrm{P}<0.05$, vs. the control; ${ }^{\#} \mathrm{P}<0.05$, vs. the OPN group. p-OPN, phosphorylated osteopontin; OA, osteoarthritis; FITC, fluorescein isothiocyanate; PI, propidium iodide.

and body fluids. Post-translational modifications (such as sulfation, O-glycosylation and phosphorylation) modulate the protein function of OPN (30). Previous studies (6-21) predominantly focused on the amount of OPN expression and demonstrated that the gene were associated with the susceptibility and severity of OA. Osteopontin has an important role in OA progression. Morimoto et al (31) considered that the role of OPN is dependent on its phosphorylation state in rheumatoid arthritis. Our previous study (22) revealed that p-OPN led to higher levels of MMP-13 expression than OPN. This prompted further investigation to determine whether phosphorylated modification of OPN has a role in apoptosis and pro-inflammatory cytokine expression in human knee OA chondrocytes. The results of the present study demonstrated that p-OPN causes cell apoptosis and production of inflammatory mediators in articular chondrocytes, two primary features of OA cartilage pathology.

Chronic, low-grade inflammation in OA contributes to the severity and symptoms of OA, as well as its progression (32). Inflammatory cytokines (such as TNF- $\alpha$, IL-1 $\beta$, IL-6 and multiple chemokines) released from various cell types are able to promote disease progression of OA by, for example, altering chondrocyte differentiation and function, and promoting synovitis and subchondral bone turnover $(33,34)$. Previously, it was observed that OPN enhanced Th1 cytokine (interferon $\gamma$ and TNF) levels and inhibited Th2 cytokine (IL-4 and IL-10) levels (35). We report herein a proinflammatory response of human knee OA chondrocytes to OPN treatment, as evidenced by the upregulation of IL- $1 \beta$, TNF- $\alpha$, IL- 6 and NF- $\kappa$ B expression at the gene and protein levels. Furthermore, p-OPN exhibited more marked proinflammatory effects on human knee OA chondrocytes through upregulation of proinflammatory cytokines (IL-1 $\beta$, TNF- $\alpha$, IL-6, NF- $\kappa \mathrm{B}$ ) at the gene and protein level compared with non-phosphorylated OPN. These results indicate that OPN or p-OPN in synovial fluid is able to initiate joint inflammation and/or aggravate the inflammatory process, potentially contributing to the development and progression of $\mathrm{OA}$.

Chondrocytes are the single cell type responsible for preserving the integrity and function of articular cartilage by synthesizing and maintaining the ECM and providing a structural framework; reduced cartilage cellularity is a hallmark of OA (36). Several processes (such as reactive oxygen species accumulation, death receptor activation, mitochondrial dysfunction and mechanical stress) are capable of causing cellular apoptosis (37). Previously, it was observed that neither $100 \mathrm{ng} / \mathrm{ml}$ nor $1 \mu \mathrm{g} / \mathrm{ml}$ rhOPN caused cytotoxicity or chondrocyte apoptosis, and that treatment with $1 \mu \mathrm{g} / \mathrm{ml} \mathrm{rhOPN}$ significantly increased the relative mRNA expression levels of tissue inhibitor of metalloproteinase (TIMP)-1 and TIMP-2 (16). These results suggest that OPN may exert protective effects 
against pathological changes in advanced-stage OA. To examine the mechanism underlying OPN or p-OPN regulation of the OA associated changes in human articular chondrocytes, the present study investigated whether OPN or p-OPN modulates apoptosis. The results demonstrated that $4 \mathrm{ng} / \mathrm{ml}$ OPN induces human articular chondrocyte apoptosis. In addition, proapoptotic and proinflammatory effects are markedly enhanced when OPN is in a phosphorylated state.

The present study had several limitations. Firstly, the potential phosphokinases of OPN were located in the consensus sequence for the mammary gland casein kinase $(\mathrm{CK})$ and the CKII consensus sequence (37), both of which are from the CK family. MAPKs were employed to act as the phosphokinase of OPN, and this may have resulted in the mis-phosphorylation of the non-OA specific phosphorylation sites. Secondly, as the native human OPN has 36 potential phosphoric sites and is highly tissue- and cell-specific for phosphorylation (37), site-specific characterization of O-glycosylation in human OPN remains poorly understood. Therefore, it is difficult to determine whether the occurrence of OA is the result of the phosphorylation of specific sites. Post-translational modifications of OPN may affect its structure and biological properties. Further investigations of phosphorylation on specific sites may provide more detailed information regarding the possible mechanism underlying the effect of OPN in OA.

In summary, OPN increases the expression levels of pro-inflammatory factors (IL-1 $\beta, \mathrm{TNF}-\alpha, \mathrm{IL}-6, \mathrm{NF}-\kappa \mathrm{B}$ ) and induces chondrocyte apoptosis. This effect can be greatly increased by OPN phosphorylation, which suggests that p-OPN may contribute to the causes and pathogenesis of knee OA. Inhibition of $\mathrm{p}-\mathrm{OPN}$ may provide a novel effective strategy to slow or halt OA progression.

\section{Acknowledgements}

This study was supported by the National Natural Science Foundation of China (grant nos. 81672225, 81201420, 81272034 and 81472130), the Natural Science Foundation of Hunan Province (grant no. 14JJ3032), the Shenhua Yuying Talent Plan of Central South University and the Huxiang Youth Talent Program. The authors are also grateful for the support of the Orthopedics Research Institute of Xiangya Hospital.

\section{References}

1. Lawrence RC, Felson DT, Helmick CG, Arnold LM, Choi H, Deyo RA, Gabriel S, Hirsch R, Hochberg MC, Hunder GG, et al: Estimates of the prevalence of arthritis and other rheumatic conditions in the United States. Part II. Arthritis Rheum 58: 26-35, 2008.

2. Liu M and Hu C: Association of MIF in serum and synovial fluid with severity of knee osteoarthritis. Clin Biochem 45: 737-739, 2012

3. Holt HL, Katz JN, Reichmann WM, Gerlovin H, Wright EA, Hunter DJ, Jordan JM, Kessler CL and Losina E: Forecasting the burden of advanced knee osteoarthritis over a 10 year period in a cohort of 60-64 year-old US adults. Osteoarthritis Cartilage 19: 44-50, 2011.

4. Sodek J, Ganss B and McKee MD: Osteopontin. Crit Rev Oral Biol Med 11: 279-303, 2000.

5. Xie Y, Sakatsume M, Nishi S, Narita I, Arakawa M and Gejyo F: Expression, roles, receptors and regulation of osteopontin in the kidney. Kidney Int 60: 1645-1657, 2001.

6. Pullig O, Weseloh G, Gauer S and Swoboda B: Osteopontin is expressed by adult human osteoarthritic chondrocytes: Protein and mRNA analysis of normal and osteoarthritic cartilage. Matrix Biol 19: 245-255, 2000.
7. Attur MG, Dave MN, Stuchin S, Kowalski AJ, Steiner G, Abramson SB, Denhardt DT and Amin AR: Osteopontin: An intrinsic inhibitor of inflammation in cartilage. Arthritis Rheum 44: 578-584, 2001.

8. Sakata M, Tsuruha JI, Masuko-Hongo K, Nakamura H, Matsui T, Sudo A, Nishioka K and Kato T: Autoantibodies to osteopontin in patients with osteoarthritis and rheumatoid arthritis. J Rheumatol 28: 1492-1495, 2001.

9. Honsawek S, Tanavalee A, Sakdinakiattikoon M, Chayanupatkul $\mathrm{M}$ and Yuktanandana P: Correlation of plasma and synovial fluid osteopontin with disease severity in knee osteoarthritis. Clin Biochem 42: 808-812, 2009.

10. Matsui Y, Iwasaki N, Kon S, Takahashi D, Morimoto J, Matsui Y, Denhardt DT, Rittling S, Minami A and Uede T: Accelerated development of aging-associated and instability-induced osteoarthritis in osteopontin-deficient mice. Arthritis Rheum 60: 2362-2371, 2009.

11. Gao SG, Li KH, Zeng KB, Tu M, Xu M and Lei GH: Elevated osteopontin level of synovial fluid and articular cartilage is associated with disease severity in knee osteoarthritis patients. Osteoarthritis Cartilage 18: 82-87, 2010.

12. Hasegawa M, Segawa T, Maeda M, Yoshida T and Sudo A: Thrombin-cleaved osteopontin levels in synovial fluid correlate with disease severity of knee osteoarthritis. J Rheumatol 38: 129-134, 2011.

13. Jiang Y, Yao M, Liu Q and Zhou C: OPN gene polymorphisms influence the risk of knee OA and OPN levels in synovial fluid in a Chinese population. Arthritis Res Ther 15: R3, 2013.

14. Gao SG, Cheng L, Zeng C, Wei LC, Zhang FJ, Tian J, Tu M, Luo W and Lei GH: Usefulness of specific OA biomarkers, thrombin-cleaved osteopontin, in the posterior cruciate ligament OA rabbit model. Osteoarthritis Cartilage 21: 144-550, 2013.

15. Zhang FJ, Yu WB, Luo W, Gao SG, Li YS and Lei GH: Effect of osteopontin on TIMP-1 and TIMP-2 mRNA in chondrocytes of human knee osteoarthritis in vitro. Exp Ther Med 8: 391-394, 2014.

16. Yang Y, Gao SG, Zhang FJ, Luo W, Xue JX and Lei GH: Effects of osteopontin on the expression of IL- 6 and IL-8 inflammatory factors in human knee osteoarthritis chondrocytes. Eur Rev Med Pharmacol Sci 18: 3580-3586, 2014.

17. Martínez-Calleja A, Velasquillo C, Vega-López M, Arellano-Jiménez MJ, Tsutsumi-Fujiyoshi VK, Mondragón-Flores R and Kouri-Flores JB: Osteopontin expression and localization of $\mathrm{Ca}++$ deposits in early stages of osteoarthritis in a rat model. Histol Histopathol 29: 925-933, 2014.

18. Weber GF, Zawaideh S, Hikita S, Kumar VA, Cantor H and Ashkar S: Phosphorylation-dependent interaction of osteopontin with its receptors regulates macrophage migration and activation. J Leukoc Biol 72: 752-761, 2002.

19. Al-Shami R, Sorensen ES, Ek-Rylander B, Andersson G, Carson DD and Farach-Carson MC: Phosphorylated osteopontin promotes migration of human choriocarcinoma cells via a p70 S6 kinase-dependent pathway. J Cell Biochem 94: 1218-1233, 2005

20. Ek-Rylander B, Flores M, Wendel M, Heinegárd D and Andersson G: Dephosphorylation of osteopontin and bone sialoprotein by osteoclastic tartrate-resistant acid phosphatase. J Biol Chem 269: 14853-14856, 1994.

21. Ek-Rylander B and Andersson G: Osteoclast migration on phosphorylated osteopontin is regulated by endogenous tartrateresistant acid phosphatase. Exp Cell Res 316: 443-451, 2010.

22. Xu M, Zhang L, Zhao L, Gao S, Han R, Su D and Lei G: Phosphorylation of osteopontin in osteoarthritis degenerative cartilage and its effect on matrix metalloprotease 13. Rheumatol Int 33: 1313-1319, 2013.

23. Blanco FJ, Guitian R, Vazquez-Martul E, de Toro FJ and Galdo F: Osteoarthritis chondrocytes die by apoptosis: A possible pathway for osteoarthritis pathology. Arthritis Rheum 41: 284-289, 1998.

24. Kim HA, Lee YJ, Seong SC, Choe KW and Song YW: Apoptotic chondrocyte death in human osteoarthritis. J Rheumatol 27: 455-562, 2000.

25. Aigner T, Soder S, Gebhard PM, McAlinden A and Haag J: Mechanisms of disease: Role of chondrocytes in the pathogenesis of osteoarthritis-structure, chaos and senescence. Nat Clin Pract Rheumatol 3: 391-399, 2007.

26. Hashimoto S, Ochs RL, Komiya S and Lotz M: Linkage of chondrocyte apoptosis and cartilage degradation in human osteoarthritis. Arthritis Rheum 41: 1632-1638, 1998. 
27. Dalal S, Zha Q, Daniels CR, Steagall RJ, Joyner WL, Gadeau AP, Singh M and Singh K: Osteopontin stimulates apoptosis in adult cardiac myocytes via the involvement of CD44 receptors, mitochondrial death pathway and endoplasmic reticulum stress. Am J Physiol Heart Circ Physiol 306: H1182-H1191, 2014.

28. Katayama Y, House CM, Udagawa N, Kazama JJ, McFarland RJ, Martin TJ and Findlay DM: Casein kinase 2 phosphorylation of recombinant rat osteopontin enhances adhesion of osteoclasts but not osteoblasts. J Cell Physiol 176: 179-187, 1998.

29. Livak KJ and Schmittgen TD: Analysis of relative gene expression data using real-time quantitative PCR and the 2(-Delta Delta C(T)) Method. Methods 25: 402-408, 2001.

30. Anborgh PH, Mutrie JC, Tuck AB and Chambers AF: Pre- and post-translational regulation of osteopontin in cancer. J Cell Commun Signal 5: 111-122, 2011.

31. Morimoto J, Kon S, Matsui Y and Uede T: Osteopontin; as a target molecule for the treatment of inflammatory diseases. Curr Drug Targets 11: 494-505, 2010.
32. Berenbaum F: Osteoarthritis as an inflammatory disease (osteoarthritis is not osteoarthrosis!). Osteoarthritis Cartilage 21: $16-21,2013$

33. Chevalier X, Eymard F and Richette P: Biologic agents in osteoarthritis: Hopes and disappointments. Nat Rev Rheumatol 9 400-410, 2013

34. Husa M, Liu-Bryan R and Terkeltaub R: Shifting HIFs in osteoarthritis. Nat Med 16: 641-644, 2010.

35. O'Regan A and Berman JS: Osteopontin: A key cytokine in cell-mediated and granulomatous inflammation. Int J Exp Pathol 81: 373-390, 2000

36. Kuhn K, D'Lima DD, Hashimoto S and Lotz M: Cell death in cartilage. Osteoarthritis Cartilage 12: 1-16, 2004

37. Christensen B, Nielsen MS, Haselmann KF, Petersen TE and Sorensen ES: Post-translationally modified residues of native human osteopontin are located in clusters: Identification of 36 phosphorylation and five O-glycosylation sites and their biological implications. Biochem J 390: 285-292, 2005. 